\title{
Self-limited uptake of $\alpha$-pinene oxide to acidic aerosol: the effects of liquid-liquid phase separation and implications for the formation of secondary organic aerosol and organosulfates from epoxides
}

\author{
G. T. Drozd, J. L. Woo, and V. F. McNeill \\ Department of Chemical Engineering, Columbia University, New York, NY, 10027, USA
}

Correspondence to: V. F. McNeill (vfm2103@columbia.edu)

Received: 5 March 2013 - Published in Atmos. Chem. Phys. Discuss.: 18 March 2013

Revised: 25 June 2013 - Accepted: 3 July 2013 - Published: 22 August 2013

\begin{abstract}
The reactive uptake of $\alpha$-pinene oxide $(\alpha \mathrm{PO})$ to acidic sulfate aerosol was studied under humid conditions in order to gain insight into the effects of liquid-liquid phase separation on aerosol heterogeneous chemistry and to elucidate further the formation of secondary organic aerosol and organosulfates from epoxides. A continuous flow environmental chamber was used to monitor changes in diameter of monodisperse, deliquesced, acidic sulfate particles exposed to $\alpha \mathrm{PO}$ at $25 \%$ and $50 \% \mathrm{RH}$ (relative humidity). In order to induce phase separation and probe potential limits to particle growth from acidic uptake, $\alpha \mathrm{PO}$ was introduced over a wide range of concentrations, from $200 \mathrm{ppb}$ to $5 \mathrm{ppm}$. Uptake was observed to be highly dependent on initial aerosol $\mathrm{pH}$. Significant uptake of $\alpha \mathrm{PO}$ to aerosol was observed with initial $\mathrm{pH}<0$. When exposed to $200 \mathrm{ppb} \alpha \mathrm{PO}$, aerosol with $\mathrm{pH}=-0.5$ showed $23 \%$ growth, and $6 \%$ volume growth was observed at $\mathrm{pH}=$ 0 . Aerosol with $\mathrm{pH}=1$ showed no growth. The extreme acidity required for efficient $\alpha \mathrm{PO}$ uptake suggests that this chemistry is typically not a major route to formation of aerosol mass or organosulfates in the atmosphere. Effective partition coefficients $\left(K_{\mathrm{p}, \text { eff }}\right)$ were in the range of $(0.1-$ 2) $\times 10^{-4} \mathrm{~m}^{3} \mu \mathrm{g}^{-1}$ and were correlated to initial particle acidity and particle organic content; particles with higher organic content had lower partition coefficients. Effective uptake coefficients $\left(\gamma_{\text {eff }}\right)$ ranged from 0.1 to $1.1 \times 10^{-4}$ and are much lower than recently reported for uptake to bulk solutions. In experiments in which $\alpha \mathrm{PO}$ was added to bulk $\mathrm{H}_{2} \mathrm{SO}_{4}$ solutions, phase separation was observed for mass loadings similar to those observed with particles, and product distributions were dependent on acid concentration.
\end{abstract}

Liquid-liquid phase separation in bulk experiments, along with our observations of decreased uptake to particles with the largest growth factors, suggests an organic coating forms upon uptake to particles, limiting reactive uptake.

\section{Introduction}

The reactive uptake of volatile organic compounds (VOCs) by tropospheric aqueous aerosols has recently gained attention as a potential source of secondary organic aerosol (SOA) and organosulfate species (Ervens et al., 2011; Lim et al., 2010; McNeill et al., 2012; Volkamer et al., 2009; Sareen et al., 2010; Kroll et al., 2005; Noziére et al., 2010; Galloway et al., 2009; Liggio et al., 2005). Volatile compounds can react in the particle phase (e.g., hydrolyzing or oligomerizing) after uptake to form lowvolatility products. Recently, interest has grown in reactive uptake for aerosols with significant water content (McNeill et al., 2012). Aqueous uptake and processing of organic matter may be important in explaining the extreme levels of oxidation $(\mathrm{O}: \mathrm{C} \geq 1)$ observed in secondary organic aerosol (Lee et al., 2011; McNeill et al., 2012). The focus of this study is the reactive uptake of epoxides to acidic sulfate aerosol and understanding the effects of particle composition on acid-mediated reactive uptake.

Epoxides have been identified as potential SOA precursors in both laboratory studies and thermodynamic calculations, in particular through their ability to form organosulfates (OSs) through acid-catalyzed ring opening (Iinuma et al., 2009; Lal et al., 2012; Minerath and Elrod, 2009; Paulot et 
al., 2009). Recent observations of OSs in ambient samples have led to laboratory studies aimed at determining their formation mechanisms and organic precursors (Surratt et al., 2006, 2007, 2008; Lin et al., 2011; Hatch et al., 2011; Lal et al., 2012; Minerath et al., 2008, 2009; Minerath and Elrod, 2009; Darer et al., 2011; Hu et al., 2011; Perri et al., 2010). OS yields are known to depend on particle acidity and total aerosol volume (Surratt et al., 2007; Iinuma et al., 2009; Lal et al., 2012; Hu et al., 2011). In addition, while initial OS formation may drive uptake to aerosol, less-substituted OSs or those with nearby electron-withdrawing groups may readily hydrolyze to diol compounds (Hu et al., 2011). A recent study employing low $\alpha \mathrm{PO}$ concentrations reacting in bulk sulfuric acid solutions did not show significant formation of organosulfates; rather unsaturated compounds formed almost exclusively following opening of the $\alpha \mathrm{PO}$ 4-member ring (Bleier and Elrod, 2013). Laboratory experiments have observed monoterpenederived epoxide uptake to extremely acidic aerosol $(\mathrm{pH} \sim$ 0 ), but results at acidities above 0 and less than 7 have not been reported. We conducted experiments over a wide range of aerosol $\mathrm{pH}$ and $\alpha \mathrm{PO}$ concentrations to explore the importance of epoxide uptake under ambient conditions.

Reactive uptake can be strongly affected by particle morphology and phase separation of particle organic and inorganic components. After liquid-liquid phase separation, a core-shell morphology with the organic phase coating the outer surface of the particle has been observed (Bertram et al., 2011; Smith et al., 2012; You et al., 2012; Song et al., 2012a, b; Ciobanu et al., 2009). Such a morphology change is expected to impact aerosol heterogeneous chemistry by changing the surface composition from aqueous to organic (You et al., 2012). Zuend and Seinfeld (2012) also showed via calculations that liquid-liquid phase separation can dramatically impact gas-particle partitioning of semivolatile species (Zuend et al., 2010; Zuend and Seinfeld, 2012). Particles with significant water content may exist in several morphologies. These could include a fully mixed aqueous/organic particle, a phase separated aqueous core with an organic shell, and an aqueous phase partially engulfed by an organic phase (Smith et al., 2012; Ciobanu et al., 2009; Kwamena et al., 2010; Reid et al., 2011; Song et al., 2012a). The organic-rich phase of phase-separated acidic particles may be proton-depleted, with the aqueous phase retaining the initial acidity (Pavia et al., 1999). In addition, uptake studies with bulk phase mimics of acidic sulfate aerosol particles (e.g., sulfuric acid solutions) do not replicate this complicated phase behavior and may only represent initial uptake rates to systems with low levels of organics. By studying uptake to both bulk solutions and particles over a range of organic content and acidities, we begin to elucidate the effects of particle morphology on uptake to acidic aerosol.

\section{Experimental methods}

\subsection{Aerosol reaction chamber setup and operation}

All chamber experiments were conducted in a $\sim 3.5 \mathrm{~m}^{3}$ Teflon chamber as shown in Fig. 1. The chamber is run in steady-state operation with a constant gas flow of $13 \mathrm{Lpm}$ for a chamber residence time of about $4 \mathrm{~h}$. Previous static chamber studies of epoxides with similar aerosol acidity, particle concentration, and $\alpha \mathrm{PO}$ concentration indicate that reactive uptake reaches steady state after about $2 \mathrm{~h}$ (Lin et al., 2011; Iinuma et al., 2009). While uptake timescales vary with particle composition and $\alpha \mathrm{PO}$ concentration, the previously observed timescales for uptake suggest our chamber residence time is long enough to accommodate complete uptake. We confirmed this experimentally, as described below.

Prior to each experiment, the bag was rinsed with deionized water and flushed with dry nitrogen to remove any material present on the chamber walls. All chamber experiments were conducted at approximately $50 \% \mathrm{RH}$ (relative humidity) and $25^{\circ} \mathrm{C}$, except for experiments with a particularly high particle acidity of $\mathrm{pH}=-1$, which were run at $25 \%$ RH. A hygrometer (Vaisala) was used to monitor the humidity and temperature of the chamber. The conditions for each experiment are listed in Table 1; also shown are the results of each experiment to be discussed below.

The bag was filled with a combination of three flows: humidified nitrogen, ammonium sulfate/sulfuric acid aerosol in nitrogen, and $\alpha \mathrm{PO}$ in nitrogen. The final humidity was adjusted by combining a nitrogen flow that passed through a water bubbler filled with de-ionized water and a second flow of dry nitrogen. The total humid-nitrogen flow was $11 \mathrm{Lpm}$. An atomizer (TSI-3076) produced seed particles by atomizing solutions of $\mathrm{H}_{2} \mathrm{SO}_{4}$ with $\left(\mathrm{NH}_{4}\right)_{2} \mathrm{SO}_{4}$ (total solute concentration $0.2 \mathrm{M}$ ) with a nitrogen flow rate of $\sim 2 \mathrm{Lpm}$. Particle acidity was altered by adjusting the ratio of $\mathrm{H}_{2} \mathrm{SO}_{4}:\left(\mathrm{NH}_{4}\right)_{2} \mathrm{SO}_{4}$ in the atomizing solution. Particle $\mathrm{pH}$ values were calculated at the designated chamber $\mathrm{RH}$ using E-AIM (Wexler and Clegg, 2002; Clegg et al., 1992; Carslaw et al., 1995; Clegg and Brimblecombe, 2005; Massucci et al., 1999), assuming particles have the same inorganic composition as the atomizing solutions. $\mathrm{pH}$ was calculated using E-AIM mole fraction-based activity data: $\mathrm{pH}=-\log _{10}\left(a_{\mathrm{H}+}\right)$. In order to achieve precise growth measurements, the atomizer output was size-selected for $150 \mathrm{~nm}$ particle diameter using a DMA (TSI-3080) operating at a $8: 0.8$ sheath to sample flow (Lpm) ratio. Particle concentrations in the bag were in the range of $1000-3000 \mathrm{~cm}^{-3} . \alpha \mathrm{PO}$ (Sigma-Aldrich, $>97 \%$ ) vapor was injected at variable concentrations by passing nitrogen over liquid $\alpha \mathrm{PO}$ held at varying temperature, which was controlled using a cold finger setup. To run below ambient temperatures, the cold finger was immersed in a dewar filled with either ice $\left(0^{\circ} \mathrm{C}\right)$ or an $\mathrm{NaCl} /$ ice bath $\left(-20^{\circ} \mathrm{C}\right)$. 


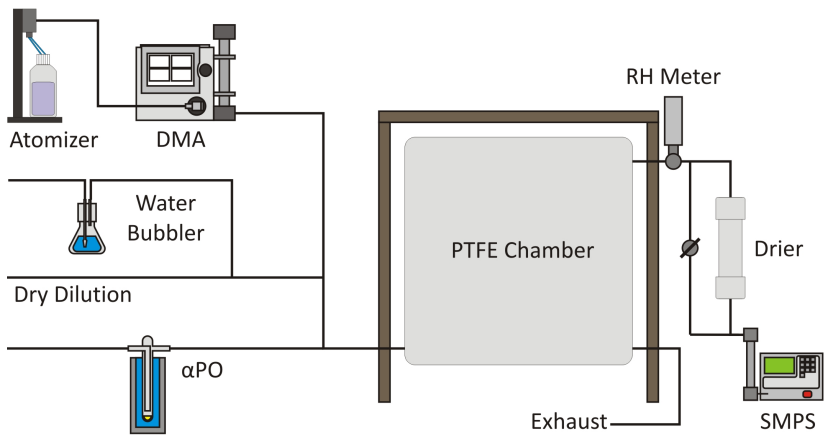

Fig. 1. Schematic of the continuous flow experimental chamber setup.

The concentration of the $\alpha \mathrm{PO}$ delivered from the cold finger was calibrated in a separate set of experiments with a custom-built chemical ionization mass spectrometer using $\mathrm{H}_{3} \mathrm{O}^{+} \cdot\left(\mathrm{H}_{2} \mathrm{O}\right)_{\mathrm{n}}$ as the reagent ion. See Sareen et al. (2010) for a description of the instrument and its operation. $\alpha \mathrm{PO}$ was detected as the protonated molecule at $\mathrm{m} / \mathrm{z}, 153$ $\left(\mathrm{C}_{10} \mathrm{H}_{16} \mathrm{O}+\mathrm{H}^{+}\right)$, its cluster with water at $\mathrm{m} / z 171$, and the protonated dimer $\left(2 \cdot \mathrm{C}_{10} \mathrm{H}_{16} \mathrm{O}+\mathrm{H}^{+}\right)$at $m / z 205$.

Data from typical experiments with a range of acidities and $\alpha \mathrm{PO}$ concentrations are shown in Fig. 2. To show all the experiments on the same axes, the measured diameters $\left(D_{\mathrm{t}}\right)$ are normalized to the final diameter $\left(D_{\mathrm{f}}\right.$ for each experiment). After a stable initial diameter measurement is achieved for the seed particles $(\sim 150 \mathrm{~nm})$, the $\alpha \mathrm{PO}$ flow was initiated. After injecting $\alpha \mathrm{PO}$ for between 4 and $8 \mathrm{~h}$, the particles in the chamber attain a stable output diameter. Previous studies using this chamber under similar operating conditions (Sareen et al., 2013) have shown that additional mixing did not perturb the outlet flow gas or aerosol concentrations, suggesting that at these flow rates and with the existing chamber configuration, the reactor is wellmixed.

\subsection{Bulk uptake studies}

\subsubsection{Gas phase uptake to bulk surfaces}

The phase behavior and diffusivity of $\alpha \mathrm{PO}$ reactive uptake products were observed in additional experiments in which gas-phase $\alpha \mathrm{PO}$ was taken up by bulk aqueous sulfuric acid samples. Four vials with $10 \mathrm{~mL}$ of sulfuric acid of varying concentration in water $(10,3,1$, and $0.1 \mathrm{M})$ and one vial with $3 \mathrm{~mL}$ of pure $\alpha \mathrm{PO}$ were placed beneath a large inverted beaker. These concentrations of the bulk solutions were picked to match roughly the $\mathrm{pH}$ values predicted by $\mathrm{E}$ AIM for the particles in the chamber experiments $(-1$, $-0.5,0,1)$. This created a sustained exposure of the acid surface to room temperature $\alpha \mathrm{PO}$ vapor $\left(0.82 \mathrm{Torr}, 25^{\circ} \mathrm{C}\right)$ (Lal et al., 2012). Vials after $18 \mathrm{~h}$ of $\alpha \mathrm{PO}$ exposure are shown in Fig. 3a. In the $10 \mathrm{M}$ acid solution, a light-red

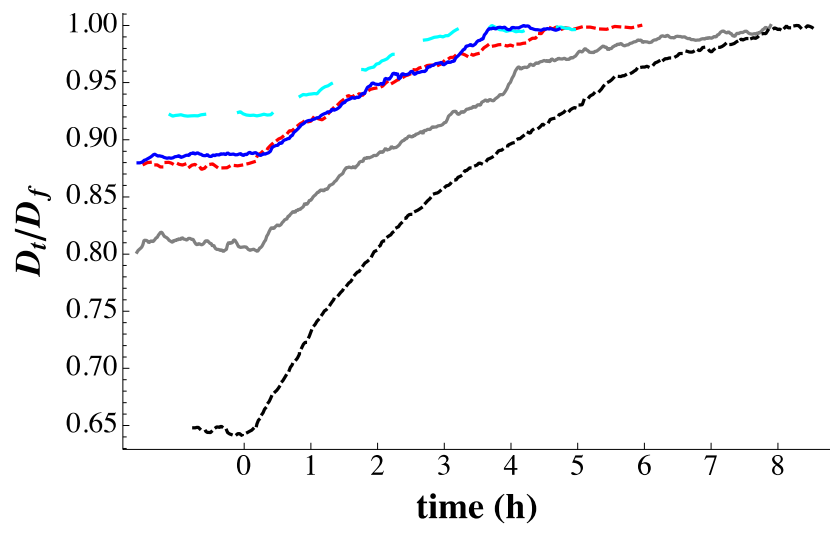

Fig. 2. Growth curves for uptake of $\alpha \mathrm{PO}$ to $\sim 150 \mathrm{~nm}$ diameter acidic sulfate particles with varying $\mathrm{pH}$ and $\alpha \mathrm{PO}$ concentrations. Blue $(\mathrm{pH}=0,[\alpha \mathrm{PO}]=5 \mathrm{ppm})$, cyan-dashed $(\mathrm{pH}=-0.5,[\alpha \mathrm{PO}]$ $=0.2 \mathrm{ppm})$, red-dashed $(\mathrm{pH}=-0.5,[\alpha \mathrm{PO}]=1 \mathrm{ppm})$, gray $(\mathrm{pH}=$ $-1,[\alpha \mathrm{PO}]=1 \mathrm{ppm})$, black-dashed $(\mathrm{pH}=-1,[\alpha \mathrm{PO}]=5 \mathrm{ppm})$. The data are aligned so that $t=0$ corresponds to the beginning of particle growth. Chamber residence time was $\sim 4 \mathrm{~h}$. Final growth values are attained within $4-8 \mathrm{~h}$.

layer was formed at the solution surface within several hours and continued to thicken with longer $\alpha \mathrm{PO}$ exposure. The $3 \mathrm{M}$ solution became slightly cloudy, and none of the other solutions formed visible products from $\alpha \mathrm{PO}$ exposure. The top and bottom layer of the acid solutions were extracted with a pipette, and the UV-Vis absorbance spectra of these fractions were measured. Digital photographs of the $10 \mathrm{M}$ reaction vials were used to monitor the time-dependent penetration of the colored reaction products into the bulk solution and estimate the aqueous-phase diffusion coefficient of $\alpha \mathrm{PO}$. Control experiments in which the acid solutions were exposed to ambient laboratory air under the trapped beaker in the absence of $\alpha \mathrm{PO}$ resulted in no color change.

\subsubsection{Slow addition of liquid $\alpha \mathrm{PO}$ to bulk acid solution}

To deliver a large volume fraction of $\alpha \mathrm{PO}, 3 \mathrm{~mL}$ of liquid $\alpha \mathrm{PO}$ was slowly added at $750 \mu \mathrm{Lh}^{-1}$ to $3 \mathrm{~mL}$ of sulfuric acid solutions with a syringe pump to achieve a $50 \%$ volume fraction of $\alpha \mathrm{PO}$ after $3 \mathrm{~h}$. In contrast to the gas-phase uptake case (Fig. 3a), for both the $10 \mathrm{M}$ and $3 \mathrm{M}$ acid concentrations, visible phase separation occurred; the vial with $10 \mathrm{M}$ acid is shown in Fig. 3b.

\section{Results and discussion}

\subsection{Uptake of $\alpha \mathrm{PO}$ to particles: effect of $\alpha \mathrm{PO}$ concentration and particle acidity}

The volume-growth factor, defined as the ratio between the final and initial volumes $\left(V_{\mathrm{f}} / V_{\mathrm{i}}\right)$, increased with the gas-phase $\alpha \mathrm{PO}$ concentration. These results are displayed 
Table 1. Summary of experimental conditions.

\begin{tabular}{|c|c|c|c|c|c|c|c|c|c|c|}
\hline Expt. \# & 1 & 2 & 3 & 4 & 5 & 6 & 7 & 8 & 9 & 10 \\
\hline Atomizing solution: $\mathrm{H}_{2} \mathrm{SO}_{4}:(\mathrm{NH} 4)_{2} \mathrm{SO}_{4}$ & $1: 0$ & $1: 0$ & $1: 0$ & $1: 0$ & $1: 0$ & $5: 3$ & $5: 3$ & $5: 3$ & $5: 9$ & $5: 9$ \\
\hline $\operatorname{Temp}\left(+/-2^{\circ} \mathrm{C}\right)$ & 26 & 26 & 26 & 26 & 26 & 26 & 26 & 26 & 26 & 26 \\
\hline $\mathrm{RH}(+/-5 \%)$ & $25 \%$ & $25 \%$ & $50 \%$ & $50 \%$ & $50 \%$ & $50 \%$ & $50 \%$ & $50 \%$ & $50 \%$ & $50 \%$ \\
\hline Aerosol $\mathrm{pH}^{\mathrm{a}}$ & -1 & -1 & -0.5 & -0.5 & -0.5 & 0 & 0 & 0 & 1 & 1 \\
\hline$\alpha \mathrm{PO}(\mathrm{ppm})$ & 5 & 1 & 5 & 1 & 0.2 & 5 & 1 & 0.2 & 5 & 1 \\
\hline Initial diameter $(\mathrm{nm})$ & 160 & 146 & 163 & 155 & 147 & 170 & 165 & 165 & 175 & 170 \\
\hline Growth factor ${ }^{b}$ & 2.55 & 1.93 & 1.92 & 1.48 & 1.23 & 1.44 & 1.1 & 1.06 & 0 & 0 \\
\hline Fraction water lost ${ }^{\mathrm{a}}$ & - & 0.30 & 0.27 & 0.42 & 0.51 & 0.45 & - & - & - & - \\
\hline Init. water content ${ }^{\mathrm{a}}(\mathrm{vol} / \mathrm{vol})$ & $41 \%$ & $41 \%$ & $52 \%$ & $52 \%$ & $52 \%$ & $24 \%$ & $24 \%$ & $24 \%$ & $24 \%$ & $24 \%$ \\
\hline
\end{tabular}

${ }^{a} \mathrm{pH}$ values calculated using atomizing solution composition in E-AIM calculations.

${ }^{\mathrm{b}}$ Ratio of final to initial particle volume: $V_{\mathrm{f}} / V_{\mathrm{i}}$.

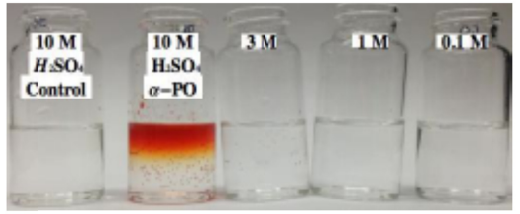

(a)

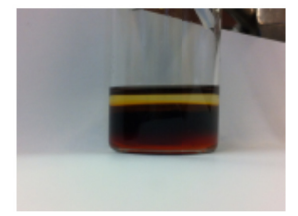

(b)
Fig. 3. (a) Photograph of vials with sulfuric acid solutions: 10, $10,3,1$, and $0.1 \mathrm{M}$ (left to right). At the far left is a control vial of $10 \mathrm{M}$ acid exposed to room air for $19 \mathrm{~h}$; the others were exposed to the room temperature vapor pressure of $\alpha \mathrm{PO}$ for $19 \mathrm{~h}$. (b) Photograph of a reaction vial with slow addition of liquid $\alpha \mathrm{PO}$ $\left(750 \mu \mathrm{Lh}^{-1}\right)$ to $10 \mathrm{M}$ acid solution. Two distinct layers are present: a dark-red bottom layer and a lighter-colored yellowish top layer. The appearance of a dark layer on top is an optical effect.

in Fig. 4 and Table 1 for experiments for several particle acidities. High particle acidity and gas-phase $\alpha \mathrm{PO}$ concentration resulted in very high growth factors and particle organic content. For particles with $\mathrm{pH} \sim-0.5$ and $5 \mathrm{ppm} \alpha \mathrm{PO}$, the growth factor is greater than 2 and the organic fraction of the particle, $\left(V_{\mathrm{f}} / V_{\mathrm{i}}-1\right) / V_{\mathrm{f}}$, reaches nearly $50 \%$.

The clear trend of increased uptake with particle acidity indicates that $\alpha \mathrm{PO}$ only forms SOA under conditions of reactive uptake. This is consistent with the relatively low aqueous solubility of $\alpha \mathrm{PO}\left(219 \mathrm{mgL}^{-1}\right.$ or roughly $0.02 \%$ by mass). Previous measurements have also shown $\alpha \mathrm{PO}$ uptake to be strongly dependent on particle acidity (Surratt et al., 2006, 2007; Lin et al., 2011; Iinuma et al., 2009; Lal et al., 2012). Iinuma et al. (2009) ran experiments with acidic $(\mathrm{pH}=0)$ and neutral aerosol, but only observed uptake at $\mathrm{pH}=0$. Surratt and co-workers also observed a strong $\mathrm{pH}$ dependence for the reactive uptake of isoprene-derived epoxides, with greater uptake at low $\mathrm{pH}$, consistent with acid-catalyzed reactions driving uptake to aerosol (Lin et al., 2011).

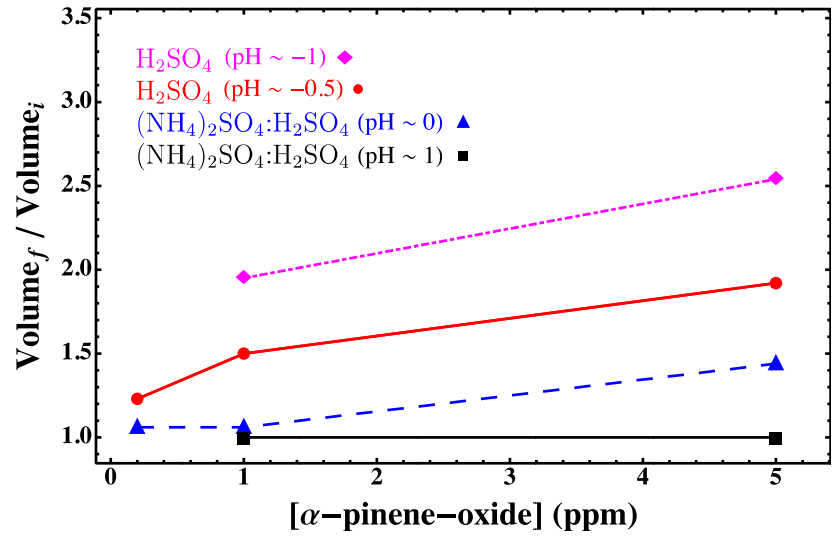

Fig. 4. Effect of acidity and $\alpha \mathrm{PO}$ concentration on the growth factor of acidic sulfate particles ( $\mathrm{pH}-1$ : magenta diamonds, $\mathrm{pH}-0.5$ : red circles, $\mathrm{pH}$ 0: blue triangles, $\mathrm{pH}$ 1: black squares). Growth due to $\alpha \mathrm{PO}$ uptake increases with acidity and $\alpha \mathrm{PO}$ concentration.

\subsection{Partitioning coefficients}

To quantify the partitioning of a gas-phase component to the aqueous aerosol, we use an effective partitioning coefficient, $K_{\mathrm{p}, \text { eff }}\left(\mathrm{m}^{3} \mu \mathrm{g}^{-1}\right)$ :

$K_{\mathrm{p}, \mathrm{eff}}=\frac{\Delta C_{\mathrm{p}, \mathrm{tot}}}{C_{\mathrm{g}} \cdot C_{\mathrm{p}, \mathrm{tot}}}$,

where $\Delta C_{\mathrm{p}, \text { tot }}$ is the increase in total particle mass concentration from gas uptake, $C_{\mathrm{g}}$ the mass concentration of organic precursor in the gas phase, and $C_{\mathrm{p}, \text { tot }}$ the total particle mass concentration, all expressed in $\mu \mathrm{g} \mathrm{m}^{-3}$. Given the chamber operating parameters, and assuming that the chamber behaves as a classical continuous-flow stirredtank reactor (CSTR), the final $C_{\mathrm{g}}$ value in the chamber will typically be within $10 \%$ and never less than $\sim 70 \%$ of the input concentration of $\alpha \mathrm{PO}$ (Fogler, 2009). The resulting uncertainty in $K_{\mathrm{p} \text {,eff }}$ is small compared to the variation in the measured $K_{\mathrm{p} \text {,eff }}$ values. The partitioning coefficient is shown as a function of particle growth factor 
in Fig. 5. A value of $2.8 \times 10^{-4} \mathrm{~m}^{3} \mu^{-1}$ was measured by Iinuma et al. (2009) under conditions of $50 \mathrm{ppb} \alpha \mathrm{PO}, 4 \times$ $10^{-6} \mathrm{~cm}^{3} \mathrm{~m}^{-3}$ seed concentration, and particles with $\mathrm{pH}=$ 0 (Iinuma et al., 2009). For that study this corresponded to a volume growth factor of $\sim 1.1$. We measured $K_{\text {p,eff }}$ under similar conditions with $200 \mathrm{ppb} \alpha \mathrm{PO}$ to be in the range of $0.4-0.6 \times 10^{-4} \mathrm{~m}^{3} \mu \mathrm{g}^{-1}$. This is good agreement given measurement uncertainty and our observation that the partitioning coefficient decreases with increasing $\alpha \mathrm{PO}$ concentration (Fig. 5).

As shown in Fig. 5, the partitioning coefficient decreases with increasing growth factor. In other words, as the organic fraction of the particle becomes greater, the affinity of $\alpha \mathrm{PO}$ for the particle decreases. The trend of uptake with growth factor suggests that changes in particle composition and/or morphology upon $\alpha \mathrm{PO}$ uptake play a major role in determining $\alpha \mathrm{PO}$ partitioning to acidic particles.

\subsection{Uptake of $\alpha \mathrm{PO}$ to bulk solutions}

The uptake of $\alpha \mathrm{PO}$ to bulk sulfuric acid solutions was strongly pH-dependent. The reactive uptake of $\alpha \mathrm{PO}$ by the $10 \mathrm{M} \mathrm{H}_{2} \mathrm{SO}_{4}$ solution was made evident by the formation of a visible red layer at the top of the solution within $3 \mathrm{~h}$. When left to sit over $48 \mathrm{~h}$, this layer darkened and grew thicker. The mass loading of $\alpha \mathrm{PO}$ in the sulfuric acid solution is low enough that phase separation is not evident. Comparing the relevant timescales in the system (uptake, reaction, and diffusion), our observation of a quickly forming yet slowly growing colored layer suggests that diffusion of organics through the liquid phase is the ratelimiting step. Due to structural similarities, we expect the diffusivities of $\alpha \mathrm{PO}$ and its reaction products to be similar. We note that, from the results of Bleier and Elrod (2013), the timescale for reaction of $\alpha \mathrm{PO}$ in $10 \mathrm{M}$ sulfuric acid will be $\sim 5 \mathrm{~min}$, suggesting a short reacto-diffusive length of $\sim 0.05 \mathrm{~cm}$. Therefore, we conclude that $\alpha \mathrm{PO}$ will react near the interface, and analysis of the depth of the colored layer can give an estimate of the diffusivity of the colored products. UV-Vis spectrophotometry confirms the formation of strongly light-absorbing products at high solution acidities and that this chemistry is reversible upon dilution with water (see Supplement). The change in thickness of the red layer over time allowed an estimate of the diffusivity for the reactive uptake products of $\alpha \mathrm{PO}$. After $45 \mathrm{~h}$ the products formed a layer roughly $1.5 \mathrm{~cm}$ thick. Fick's law (Eq. 2) gives a relationship between diffusivity, $D$, the distance traveled in a given direction, $x$, and the elapsed time, $t$ :

$D=\frac{x^{2}}{2 t}$

For our system, $x$ is the depth of the colored layer, or the distance from the solution surface to the bottom of the colored region, and $t$ is the elapsed time after beginning exposure to $\alpha \mathrm{PO}$. The diffusivity of the reaction products

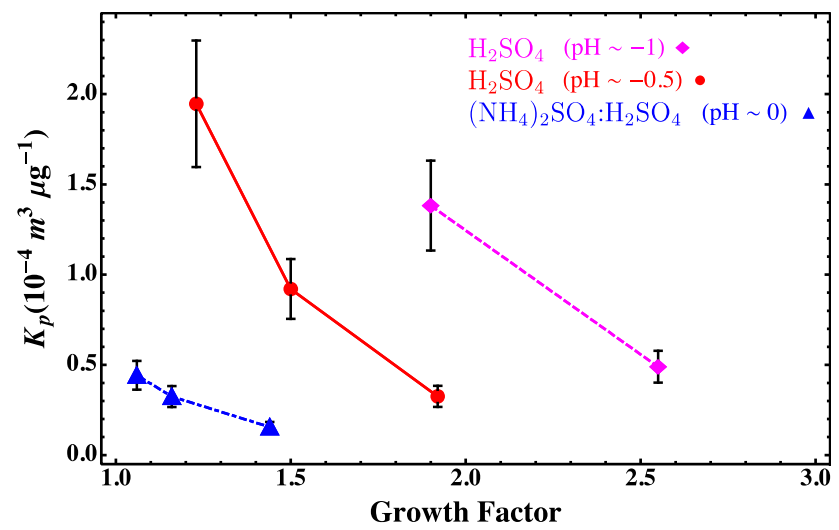

Fig. 5. Effective partitioning coefficients as a function of particle growth factor. Data are shown for three particle $\mathrm{pH}$ levels: -1 (magenta diamonds), -0.5 (red circles), 0 (blue triangles). Partitioning coefficients increase with increasing particle acidity and decrease with increasing growth factor.

is calculated to be $9 \times 10^{-6} \mathrm{~cm}^{2} \mathrm{~s}^{-1}$. This value is similar to the room temperature, low-concentration limit of glucose in water (Gladden and Dole, 1953), and does not indicate particularly low diffusivity.

Liquid-liquid phase separation was observed at higher mass loadings of $\alpha \mathrm{PO}$. Using a syringe pump, liquid $\alpha \mathrm{PO}$ was slowly injected to the surface of sulfuric acid solutions. The flow rate was set to give a similar volume-addition rate of $\alpha \mathrm{PO}$ to the acid solution as was observed in the particle uptake experiments, doubling the solution volume over $3 \mathrm{~h}$. Phase separation occurred for both the 10 and $3 \mathrm{M}$ sulfuric acid solutions, but the organic phase in the $3 \mathrm{M}$ solutions was not colored, consistent with our other bulk experiments. The $\alpha \mathrm{PO}$ concentration in a solution or particle will affect the product distribution, because a higher organic concentration will favor oligomerization. Lal et al. (2012) observed a change in the product distribution in bulk studies of the mixed liquids with different $\alpha \mathrm{PO}$ : acid mass ratios, suggesting that the concentration of organics at the bulk surface or in a particle affects the product distribution. Standard organic synthesis has shown that, at least in bulk sulfuric acid solutions, the hydrolysis products involve opening of the 4-member ring in $\alpha \mathrm{PO}$ (Coelho et al., 2012). This reaction mechanism was also evident in the recent work of Bleier and Elrod (2013). This chemistry is not likely to be reversible and retains a double bond that will allow for further reaction, such as oligomerization at high $\alpha \mathrm{PO}$ concentrations. The estimation of relatively fast diffusion rates in these systems and the decreased $K_{\mathrm{p}}$ values in high-mass loading experiments suggest that products of $\alpha \mathrm{PO}$ uptake will saturate the particle volume and then phase separate with increased loading. 


\subsection{Loss of water upon drying}

Particles were dried after organic uptake in order to get more information about their phase/morphology. The results from drying are shown in Table 1 and also Fig. 6 as diameter growth vs. the fraction of water lost from the particle. The fraction of water lost is calculated as

$$
F_{\text {loss }}=\frac{V_{\text {wet }}-V_{\text {dry }}}{V\left(\mathrm{H}_{2} \mathrm{O}\right)_{\mathrm{RH}, \text { wet }}-V\left(\mathrm{H}_{2} \mathrm{O}\right)_{\mathrm{RH}, \mathrm{dry}}},
$$

where $V_{\text {wet }}$ and $V_{\text {dry }}$ are the particle volumes before and after the drier, and $V\left(\mathrm{H}_{2} \mathrm{O}\right)_{\mathrm{RH}}$, wet and $V\left(\mathrm{H}_{2} \mathrm{O}\right)_{\mathrm{RH}}$,dry are the volumes of water at the $\mathrm{RH}$ conditions before and after the drier. The volumes of water were calculated using EAIM, models I and II (Wexler and Clegg, 2002; Clegg et al., 1992; Carslaw et al., 1995; Clegg and Brimblecombe, 2005; Massucci et al., 1999). We observe a clear trend in the fraction of the total particle water lost with the increase in particle diameter. Greater particle diameter growth (i.e., a thicker organic coating) was correlated with decreased water loss from the particles. The residence time in the drier was $\sim 7 \mathrm{~s}$. It may be the case that on longer timescales (from $\sim 1$ min to several minutes) particles may reach equilibrium. Nonetheless, our results suggest that the organic component of the particle inhibited water evaporation, as we discuss in the following paragraphs.

Varying particle size and changes in water activity may partially explain the trend in particle organic content. Given the relation between particle diameter $\left(d_{\mathrm{p}}\right)$, diffusion coefficient $(D)$ and equilibration time $\left(\tau_{D}\right)$ (Shiraiwa et al., 2011),

$\tau_{D} \propto \frac{d_{\mathrm{p}}^{2}}{D}$,

the variation in the relative amounts of drying is greater than would be explained by the variation in particle diameter alone. As seen in Fig. 7, the variation in final particle diameter is $\sim 152-182 \mathrm{~nm}$, which would only give rise to $\sim 30 \%$ variation in equilibration timescales. The diffusivity of the particles is indeed likely to decrease with increased organic material, regardless of particle morphology, but particle size alone does not explain the variability in approach to equilibrium. This suggests that at least the effective water diffusivity may decrease significantly with higher particle fractions of $\alpha$ PO SOA.

Another possible cause for the variation in the fraction of water loss is a change in the water activity of the particles after organic deposition. Water activity can be calculated as (Bilde and Svenningsson, 2004)

$a_{\mathrm{w}}=\gamma_{\mathrm{w}} \frac{n_{\mathrm{w}}}{n_{\mathrm{w}}+\sum_{\mathrm{s}} i_{\mathrm{s}} n_{\mathrm{s}}}$,

where $\gamma_{\mathrm{w}}$ is the activity coefficient for water, $n_{\mathrm{w}}$ the moles of water, $i_{\mathrm{s}}$ the van't Hoff factor for solute species "s",

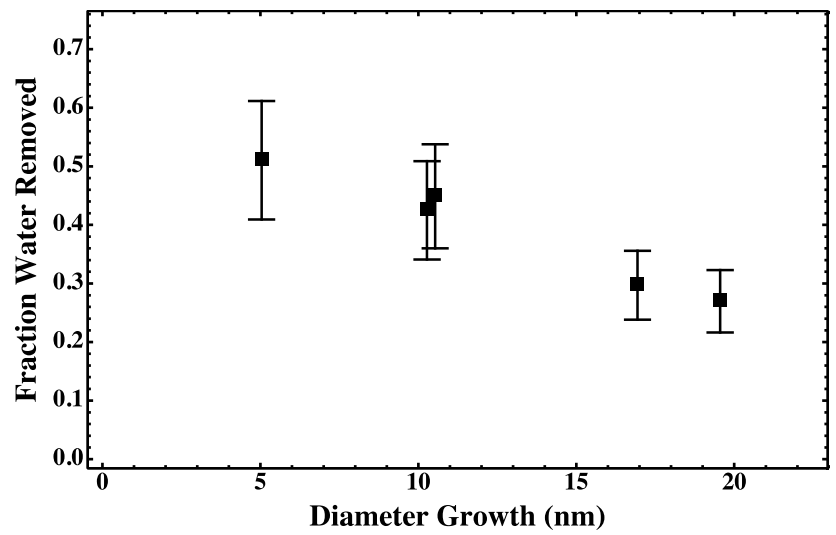

Fig. 6. Fraction of water removed during drying from particles after uptake of $\alpha \mathrm{PO}$ vs. diameter growth.

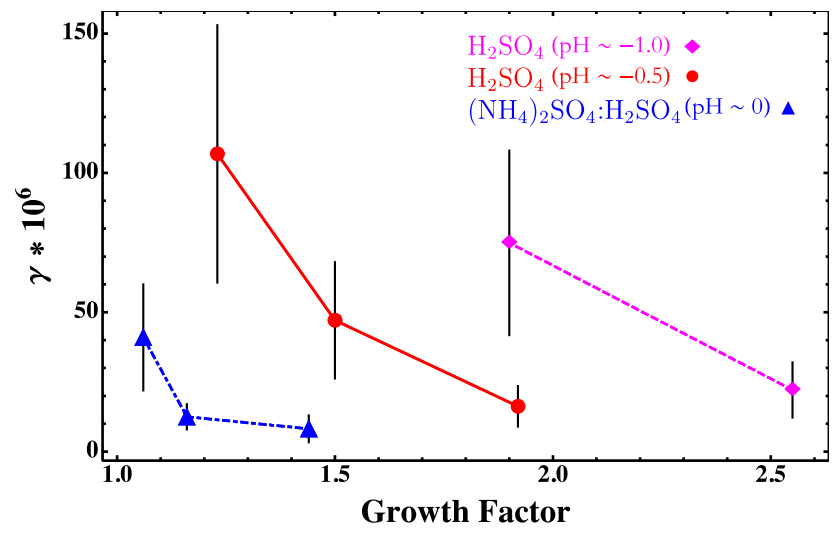

Fig. 7. Uptake coefficient dependence on growth factor for particles in the $\mathrm{pH}$ range of -1 to 0 . Calculated $\mathrm{pH}$ values for the seed aerosol are -1 (magenta diamonds), -0.5 (red circles), and 0 (blue triangles).

and $n_{\mathrm{s}}$ the moles of solutes "s". The variation in water activity for our systems was calculated using this equation with the molalities of the inorganic species (including water) predicted from E-AIM and assuming the $\alpha \mathrm{PO}$ SOA organic material to have a density of $1 \mathrm{~g} \mathrm{~cm}^{-3}$, van't Hoff factor of 1 , and a molecular weight of $150 \mathrm{~g} \mathrm{~mol}^{-1}$. The Raoult's law (mole fraction) part of the water activity expression only explains about $7 \%$ of the variation in water evaporation, much less than the factor of 2 exhibited. Thus the variation in fraction of water lost would be parameterized, empirically, in varying the water activity coefficient.

The trend in water loss due to drying will be partially due to differences in equilibration timescales and the mole fractions of water present. Empirically this could be represented as a change in the water activity coefficient for particles with different amounts of $\alpha \mathrm{PO}$ SOA. The large variation in activity coefficients is not inconsistent with formation of an organic coating. 
Separation of the particles into water-rich and organic-rich liquid phases is suggested by our bulk-phase studies. This is consistent with recent studies by Bertram et al. (2011), which showed phase separation for particles of ammonium sulfate and organic compounds that have atomic $\mathrm{O}: \mathrm{C}$ ratios of less than 0.7 , and product studies of $\alpha \mathrm{PO}+\mathrm{H}_{2} \mathrm{SO}_{4}$ suggest material with $\mathrm{O}: \mathrm{C}$ of $0.2-0.5$ is formed (Lal et al., 2012; Iinuma et al., 2009; Coelho et al., 2012; Song et al., 2012b). In their studies, Bertram et al. (2011) observed a core-shell morphology for phase-separated particles, with the organic phase on the outside. Inhibition of water loss from particles with high organic content is consistent with slow diffusion of water out of the particle through the organic-rich phase of the particle. The observed trend in water loss highlights the potential importance of phase separation in predicting water uptake/loss.

\subsection{Uptake coefficients}

The dynamic uptake of gases to the particle surface is determined by the uptake coefficient. It characterizes the collision efficiency for uptake of an organic molecule to a surface. Assuming a set timescale to grow to the final diameter, we can estimate this parameter, and then compare this value to previous measurements and values for similar cases. Our experiments do not directly yield the timescale to reach the final growth factor, because the experimental timescale is determined by the time to reach steady state in the continuous-flow chamber. We can use the estimate of $\sim 1.5 \mathrm{~h}$ from the batch reactor experiments of Iinuma et al. (2009) as a guide. Assuming a constant particle density, there is a simple relation between the mass flux and molecular collision with a particle that yields the effective uptake coefficient (Seinfeld and Pandis, 2006):

$\Delta D_{\mathrm{p}}=\frac{\gamma_{\mathrm{eff}} \omega C_{\mathrm{gas}} \mathrm{MW}_{\mathrm{gas}}}{4 \rho} \Delta t$,

where $\Delta D_{\mathrm{p}}$ is the change in particle diameter, $\gamma_{\text {eff }}$ the uptake coefficient, $\omega$ the molecular speed, $C_{\text {gas }}$ the condensing species' gas-phase concentration, $\mathrm{MW}_{\text {gas }}$ the molecular weight of the condensing species, $\rho$ the particle density, and $\Delta t$ the duration of condensation. As a first approximation, we can use this relation to calculate an average uptake coefficient during the course of an experiment. Using the timescale from Iinuma et al. (2009), we calculate reactive uptake coefficients between $1 \times 10^{-6}$ and $110 \times 10^{-6}$. These values, shown in Fig. 7, are particularly low for reactive uptake of organics. Lal et al. (2012) have measured uptake coefficients for $\alpha \mathrm{PO}$ to bulk sulfuric acid surfaces to be $4.6 \times 10^{-2}$, and uptake coefficients for other reactive organics are in the range of $1 \times 10^{-3}$ (Lal et al., 2012; Liggio et al., 2005). The absorbing phase in the previous studies of $\alpha \mathrm{PO}$ to bulk solution does not reach high volume fractions of organics, so these measurements might reflect only initial uptake of $\alpha \mathrm{PO}$ to particles, before accumulation (or without the presence) of organic material. Our low values for the effective uptake coefficients show that the uptake coefficient depends on the volume fraction of organics and decreases as the particle accumulates organic material. Since $\alpha \mathrm{PO}$ uptake is driven by reaction with acid in the aqueous phase, this is again consistent with the formation of an organic-rich phase at the gas-aerosol interface.

\section{Conclusions}

We have demonstrated via bulk and aerosol chamber measurements that the reactive uptake of $\alpha \mathrm{PO}$ to acidic aerosol is self-limiting. Liquid-liquid phase separation at high organic loadings, supported by experiments with bulk mixtures, is a likely cause of this phenomenon. Both the effective partition coefficients and uptake coefficients decreased for particles with higher volume fractions of organics, and inhibited water loss was observed at high organic loadings. In experiments using bulk solutions, phase separation was observed for solutions with high volume fractions of $\alpha \mathrm{PO}$ and its reaction products. Similar effects are possible for aqueous aerosol SOA formation in other systems with $\mathrm{O}: \mathrm{C}$ ratios $<0.7$ (and therefore liquid-liquid phase separation is predicted) (Bertram et al., 2011; Song et al., 2012b). In scenarios where isoprene epoxydiols or glyoxal dominates uptake to the aerosol aqueous phase, the $\mathrm{O}: \mathrm{C}$ ratio is expected to be $>0.7$, so this effect may not limit SOA formation via those pathways (McNeill et al., 2012). However, more experimental evidence is needed to confirm this prediction.

To date, studies have only shown uptake of monoterpenederived epoxides at an aerosol $\mathrm{pH}$ of zero. Our results support this fact and show that, even at an aerosol $\mathrm{pH}$ of 1.0, no observable uptake occurred for $\alpha \mathrm{PO}$. This suggests that, under typical ambient conditions, significant formation of monoterpene-derived SOA or organosulfate compounds is not likely to occur. Both our observations of complex phase behavior and $\mathrm{pH}$-dependent product formation suggest that flow tube measurements of epoxide uptake to bulk solutions may only apply to particles with low organic content and equivalent acidity, and that particle organic content strongly affects product yields/identities.

\section{Supplementary material related to this article is available online at: http://www.atmos-chem-phys.net/13/ 8255/2013/acp-13-8255-2013-supplement.pdf.}

Acknowledgements. This work was supported by the Camille \& Henry Dreyfus Foundation Postdoctoral Program in Environmental Chemistry and the NASA Tropospheric Chemistry program (Grant NNX09AF26G).

Edited by: D. Topping 


\section{References}

Bertram, A. K., Martin, S. T., Hanna, S. J., Smith, M. L., Bodsworth, A., Chen, Q., Kuwata, M., Liu, A., You, Y., and Zorn, S. R.: Predicting the relative humidities of liquid-liquid phase separation, efflorescence, and deliquescence of mixed particles of ammonium sulfate, organic material, and water using the organic-to-sulfate mass ratio of the particle and the oxygen-tocarbon elemental ratio of the organic component, Atmos. Chem. Phys., 11, 10995-11006, doi:10.5194/acp-11-10995-2011, 2011.

Bilde, M. and Svenningsson, B.: CCN activation of slightly soluble organics: the importance of small amounts of inorganic salt and particle phase, Tellus B, 56, 128-134, doi:10.1111/j.16000889.2004.00090.x, 2004.

Bleier, D. B., and Elrod, M. J.: Kinetics and Thermodynamics of Atmospherically Relevant Aqueous Phase Reactions of $\alpha$-Pinene Oxide, J. Phys. Chem. A, 117, 4223-4232, doi:10.1021/jp402093x, 2013.

Carslaw, K. S., Clegg, S. L., and Brimblecombe, P.: A thermodynamic model of the system $\mathrm{HCl}-\mathrm{HNO}_{3}-\mathrm{H}_{2} \mathrm{SO}_{4}-\mathrm{H}_{2} \mathrm{O}$, including solubilities of $\mathrm{HBr}$ from $<200 \mathrm{~K}$ to $328 \mathrm{~K}$, J. Phys. Chem., 99, 11557-11574, 1995.

Ciobanu, V. G., Marcolli, C., Krieger, U. K., Weers, U., and Peter, T.: Liquid-Liquid Phase Separation in Mixed Organic/Inorganic Aerosol Particles, J. Phys. Chem. A, 113, 10966-10978, 2009.

Clegg, S. L. and Brimblecombe, P.: Comment on the "Thermodynamic Dissociation Constant of the Bisulfate Ion from Raman and Ion Interaction Modeling Studies of Aqueous Sulfuric Acid at Low Temperatures" by Knopf et al., J. Phys. Chem. A., 109, 2703-2706, 2005.

Clegg, S. L., Pitzer, K. S., and Brimblecombe, P.: Thermodynamics of multicomponent, miscible, ionic solutions. II. Mixtures including unsymmetrical electrolytes, J. Phys. Chem., 96, 94709479, 1992.

Coelho, J. V., de Meireles, A. L. P., da Silva Rocha, K. A., Pereira, M. C., Oliveira, L. C. A., and Gusevskaya, E. V.: Isomerization of $\alpha$-pinene oxide catalyzed by iron-modified mesoporous silicates, Applied Catalysis A: General, 443-444, 125-132, doi:10.1016/j.apcata.2012.07.030, 2012.

Darer, A. I., Cole-Filipiak, N. C., O'Connor, A. E., and Elrod, M. J.: Formation and Stability of Atmospherically Relevant Isoprene-Derived Organosulfates and Organonitrates, Environ. Sci. Technol., 45, 1895-1902, doi:10.1021/es103797z, 2011.

Ervens, B., Turpin, B. J., and Weber, R. J.: Secondary organic aerosol formation in cloud droplets and aqueous particles (aqSOA): a review of laboratory, field and model studies, Atmos. Chem. Phys., 11, 11069-11102, doi:10.5194/acp-1111069-2011, 2011.

Fogler, H. S.: Elements of Chemical Reaction Engineering, Prentice Hall, New Jersey, 2009.

Galloway, M. M., Chhabra, P. S., Chan, A. W. H., Surratt, J. D., Flagan, R. C., Seinfeld, J. H., and Keutsch, F. N.: Glyoxal uptake on ammonium sulphate seed aerosol: reaction products and reversibility of uptake under dark and irradiated conditions, Atmos. Chem. Phys., 9, 3331-3345, doi:10.5194/acp-9-33312009, 2009.

Gladden, J. K. and Dole, M.: Diffusion in Supersaturated Solutions. II. Glucose Solutions, J. Am. Chem. Soc., 75, 3900-3904, doi:10.1021/ja01112a008, 1953.
Hatch, L. E., Creamean, J. M., Ault, A. P., Surratt, J. D., Chan, M. N., Seinfeld, J. H., Edgerton, E. S., Su, Y., and Prather, K. A.: Measurements of Isoprene-Derived Organosulfates in Ambient Aerosols by Aerosol Time-of-Flight Mass Spectrometry - Part 2: Temporal Variability and Formation Mechanisms, Environ. Sci. Technol., 45, 8648-8655, doi:10.1021/es2011836, 2011.

Hu, K. S., Darer, A. I., and Elrod, M. J.: Thermodynamics and kinetics of the hydrolysis of atmospherically relevant organonitrates and organosulfates, Atmos. Chem. Phys., 11, 8307-8320, doi:10.5194/acp-11-8307-2011, 2011.

Iinuma, Y., Boge, O., Kahnt, A., and Herrmann, H.: Laboratory chamber studies on the formation of organosulfates from reactive uptake of monoterpene oxides, Phys. Chem. Chem. Phys., 11, 7985-7997, doi:10.1039/b904025k, 2009.

Kroll, J. H., Ng, N. L., Murphy, S. M., Varutbangkul, V., Flagan, R. C., and Seinfeld, J. H.: Chamber studies of secondary organic aerosol growth by reactive uptake of simple carbonyl compounds, J. Geophys. Res., 110, D23207, doi:10.1029/2005jd006004, 2005.

Kwamena, N. O. A., Buajarern, J., and Reid, J. P.: Equilibrium Morphology of Mixed Organic/Inorganic/Aqueous Aerosol Droplets: Investigating the Effect of Relative Humidity and Surfactants, J. Phys. Chem. A, 114, 5787-5795, 2010.

Lal, V., Khalizov, A. F., Lin, Y., Galvan, M. D., Connell, B. T., and Zhang, R.: Heterogeneous Reactions of Epoxides in Acidic Media, J. Phys. Chem. A, 6078-6090, doi:10.1021/jp2112704, 2012.

Lee, A. K. Y., Herckes, P., Leaitch, W. R., Macdonald, A. M., and Abbatt, J. P. D.: Aqueous $\mathrm{OH}$ oxidation of ambient organic aerosol and cloud water organics: Formation of highly oxidized products, Geophys. Res. Lett., 38, L11805, doi:10.1029/2011 g1047439, 2011.

Liggio, J., Li, S.-M., and McLaren, R.: Reactive uptake of glyoxal by particulate matter, J. Geophys. Res., 110, D10304, doi:10.1029/2004jd005113, 2005.

Lim, Y. B., Tan, Y., Perri, M. J., Seitzinger, S. P., and Turpin, B. J.: Aqueous chemistry and its role in secondary organic aerosol (SOA) formation, Atmos. Chem. Phys., 10, 1052110539, doi:10.5194/acp-10-10521-2010, 2010.

Lin, Y.-H., Zhang, Z., Docherty, K. S., Zhang, H., Budisulistiorini, S. H., Rubitschun, C. L., Shaw, S. L., Knipping, E. M., Edgerton, E. S., Kleindienst, T. E., Gold, A., and Surratt, J. D.: Isoprene Epoxydiols as Precursors to Secondary Organic Aerosol Formation: Acid-Catalyzed Reactive Uptake Studies with Authentic Compounds, Environ. Sci. Technol., 46, 250258, doi:10.1021/es202554c, 2011.

Massucci, M., Clegg, S. L., and Brimblecombe, P.: Equilibrium partial pressures, thermodynamic properties of aqueous and solid phases, and $\mathrm{Cl}_{2}$ production from aqueous $\mathrm{HCl}$ and $\mathrm{HNO}_{3}$ and their mixtures, J. Phys. Chem. A, 103, 4209-4226, 1999.

McNeill, V. F., Woo, J. L., Kim, D. D., Schwier, A. N., Wannell, N. J., Sumner, A. J., and Barakat, J. M.: Aqueous-phase secondary organic aerosol and organosulfate formation in atmospheric aerosols: a modeling study, Environ. Sci. Technol., 46, 80758081, doi:10.1021/es3002986, 2012.

Minerath, E. C. and Elrod, M. J.: Assessing the Potential for Diol and Hydroxy Sulfate Ester Formation from the Reaction of Epoxides in Tropospheric Aerosols, Environ. Sci. Technol., 43, 1386-1392, doi:10.1021/es8029076, 2009. 
Minerath, E. C., Casale, M. T., and Elrod, M. J.: Kinetics Feasibility Study of Alcohol Sulfate Esterification Reactions in Tropospheric Aerosols, Environ. Sci. Technol., 42, 4410-4415, doi:10.1021/es8004333, 2008.

Minerath, E. C., Schultz, M. P., and Elrod, M. J.: Kinetics of the Reactions of Isoprene-Derived Epoxides in Model Tropospheric Aerosol Solutions, Environ. Sci. Technol., 43, 8133-8139, doi:10.1021/es902304p, 2009.

Noziére, B., Dziedzic, P., and Córdova, A.: Inorganic ammonium salts and carbonate salts are efficient catalysts for aldol condensation in atmospheric aerosols, Phys. Chem. Chem. Phys., 12, 3864-3872, 2010.

Paulot, F., Crounse, J. D., Kjaergaard, H. G., Kurten, A., St. Clair, J. M., Seinfeld, J. H., and Wennberg, P. O.: Unexpected Epoxide Formation in the Gas-Phase Photooxidation of Isoprene, Science, 325, 730-733, 2009.

Pavia, D., Lampman, G., and Kriz, G.: Organic Laboratoy Techniques, 3rd Edn., Brooks/Cole, Pacific Grove, CA, 1999.

Perri, M. J., Lim, Y. B., Seitzinger, S. P., and Turpin, B. J.: Organosulfates from glycolaldehyde in aqueous aerosols and clouds: Laboratory studies, Atmos. Environ., 44, 2658-2664, doi:10.1016/j.atmosenv.2010.03.031, 2010.

Reid, J. P., Dennis-Smither, B. J., Kwamena, N. O. A., Miles, R. E. H., Hanford, K. L., and Homer, C. J.: The morphology of aerosol particles consisting of hydrophobic and hydrophilic phases: hydrocarbons, alcohols and fatty acids as the hydrophobic component, Phys. Chem. Chem. Phys., 13, 15559-15572, 2011.

Sareen, N., Schwier, A. N., Shapiro, E. L., Mitroo, D., and McNeill, V. F.: Secondary organic material formed by methylglyoxal in aqueous aerosol mimics, Atmos. Chem. Phys., 10, 997-1016, doi:10.5194/acp-10-997-2010, 2010.

Sareen, N., Schwier, A. N., Lathem, T. L., Nenes, A., and McNeill, V. F.: Surfactants from the gas phase may promote cloud droplet formation, P. Natl. Acad. Sci. USA, 110, 2723-2728, 2013.

Seinfeld, J. H. and Pandis, S. N.: Atmospheric Chemistry and Physics, 2nd Edn., Wiley, Hoboken, New Jersy, 2006.

Shiraiwa, M., Ammann, M., Koop, T., and Pöschl, U.: Gas uptake and chemical aging of semisolid organic aerosol particles, P. Natl. Acad. Sci. USA, 108, 11003-11008, doi:10.1073/pnas.1103045108, 2011.

Smith, M. L., Bertram, A. K., and Martin, S. T.: Deliquescence, efflorescence, and phase miscibility of mixed particles of ammonium sulfate and isoprene-derived secondary organic material, Atmos. Chem. Phys., 12, 9613-9628, doi:10.5194/acp12-9613-2012, 2012.

Song, M., Marcolli, C., Krieger, U. K., Zuend, A., and Peter, T.: Liquid-liquid phase separation and morphology of internally mixed dicarboxylic acids/ammonium sulfate/water particles, Atmos. Chem. Phys., 12, 2691-2712, doi:10.5194/acp-12-26912012, 2012a.
Song, M., Marcolli, C., Krieger, U. K., Zuend, A., and Peter, T.: Liquid-liquid phase separation in aerosol particles: Dependence on O:C, organic functionalities, and compositional complexity, Geophys. Res. Lett., 39, L19801, doi:10.1029/2012g1052807, 2012b.

Surratt, J. D., Kroll, J. H., Kleindienst, T. E., Edney, E. O., Claeys, M., Sorooshian, A., Ng, N. L., Offenberg, J. H., Lewandowski, M., Jaoui, M., Flagan, R. C., and Seinfeld, J. H.: Evidence for Organosulfates in Secondary Organic Aerosol, Environ. Sci. Technol., 41, 517-527, doi:10.1021/es062081q, 2006.

Surratt, J. D., Lewandowski, M., Offenberg, J. H., Jaoui, M., Kleindienst, T. E., Edney, E. O., and Seinfeld, J. H.: Effect of Acidity on Secondary Organic Aerosol Formation from Isoprene, Environ. Sci. Technol., 41, 5363-5369, doi:10.1021/es0704176, 2007.

Surratt, J. D., Goméz-González, Y., Chan, A. W. H., Vermeylen, R., Shahgholi, M., Kleindienst, T. E., Edney, E. O., Offenberg, J. H., Lewandowski, M., Jaoui, M., Maenhaut, W., Claeys, M., Flagan, R. C., and Seinfeld, J. H.: Organosulfate Formation in Biogenic Secondary Organic Aerosol, J. Phys. Chem. A, 112, 8345-8378, doi:10.1021/jp802310p, 2008.

Volkamer, R., Ziemann, P. J., and Molina, M. J.: Secondary Organic Aerosol Formation from Acetylene $\left(\mathrm{C}_{2} \mathrm{H}_{2}\right)$ : seed effect on SOA yields due to organic photochemistry in the aerosol aqueous phase, Atmos. Chem. Phys., 9, 1907-1928, doi:10.5194/acp-91907-2009, 2009.

Wexler, A. S. and Clegg, S. L.: Atmospheric aerosol models for systems including the ions $\mathrm{H}^{+}, \mathrm{NH}_{4}^{+}, \mathrm{Na}^{+}, \mathrm{SO}_{4}^{2-}$, $\mathrm{NO}_{3}^{-}, \mathrm{Cl}^{-}, \mathrm{Br}^{-}$and $\mathrm{H}_{2} \mathrm{O}$, J. Geophys. Res., 107, D4207, doi:10.1029/2001JD000451, 2002.

You, Y., Renbaum-Wolff, L., Carreras-Sospedra, M., Hanna, S. J., Hiranuma, N., Kamal, S., Smith, M. L., Zhang, X., Weber, R. J., Shilling, J. E., Dabdub, D., Martin, S. T., and Bertram, A. K.: Images reveal that atmospheric particles can undergo liquidliquid phase separations, P. Natl. Acad. Sci. USA, 109, 1318813193, doi:10.1073/pnas.1206414109, 2012.

Zuend, A., Marcolli, C., Peter, T., and Seinfeld, J. H.: Computation of liquid-liquid equilibria and phase stabilities: implications for RH-dependent gas/particle partitioning of organic-inorganic aerosols, Atmos. Chem. Phys., 10, 7795-7820, doi:10.5194/acp10-7795-2010, 2010.

Zuend, A. and Seinfeld, J. H.: Modeling the gas-particle partitioning of secondary organic aerosol: the importance of liquidliquid phase separation, Atmos. Chem. Phys., 12, 3857-3882, doi:10.5194/acp-12-3857-2012, 2012. 